\title{
SMART SPECIALISATION STRATEGY ASSESSMENT IN BALTIC STATES
}

\author{
Sergejs Gemma, Zane Bulderberga \\ Latvian University of Agriculture \\ Sergejs.Gemma@1lu.lv
}

\begin{abstract}
Smart specialisation strategy (RIS3) is topical for each European Union member state - including the Baltic States. It is a smart tool for the European Union (EU) Structural Funds absorption from 2014 to 2020. Each EU member state has set their own priorities based on the country specialisation and economy strengths and weaknesses. For RIS3 development evaluation, there is RIS3 Assessment Wheel developed - a tool for assessing the RIS3 in a chosen region and positioning it between other regions. The aim of research is to find main differences between RIS3 development in the Baltic states. The tasks of research are 1) to compare existing RIS3 Assessment Wheel of Latvia and create authors version of RIS3 Assessment Wheel of Latvia; 2) to create RIS3 Assessment Wheel of Lithuania and Estonia; 3) to make comparisons between created RIS3 Assessment Wheels. The research performed is mainly based on the desk research by using content analysis and the monographic method. In all three Baltic States, there is a lack of information available about revision of priorities in connection with RIS3 development. In order to achieve the aims set in RIS3, it is essential to finish work on RIS3 legislation in Latvia, and introduce the systematic approach to RIS3 target evaluation in all Baltic States.
\end{abstract}

Key words: smart specialisation strategy, RIS3 Assessment Wheel, Baltic States.

\section{Introduction}

National strategy for smart specialization has an ex ante conditionality for the European Union (EU) Structural Funds use from 2014 to 2020 . The strategy envisages detecting smart specialisation priorities with the greatest potential to increase the competitiveness of national economies and mobilising resources for implementing the priorities (Boekholt et al., 2015). Smart specialisation is also topical for Baltic States as the EU Member States. The main aim of the smart specialization strategy (RIS3) in Latvia is to increase innovation capacity and to create an innovation system that promotes and supports technological progress of economy (Informatīvais ziņojums "Par..., 2013). Lithuanian RIS3 priority is defined as the development and commercialisation of thematicallyfocused, innovative technologies or processes that have high potential to transform the Lithuanian economy, while concentrating available research, development and innovation potential and responding to global tendences and challenges (Martinaitis et al., 2013).The goal of smart specialisation in Estonia is to become more competitive, the country must move up in the production chain and concentrate more on innovation and development, finding areas that increase their efficiency, avoiding relying mainly on low wage levels as their competitive edge (Estonian Development Fund, 2013).

For assessing the smart specialization strategy in a chosen region and positioning it between other regions, Joint Research Centre by European Commission has published the RIS3 Assessment Wheel. It is a synthetic tool allowing condensing a big amount of information in one model which shows the smart specialization development in chosen region. In Latvia, there are already two opinions of the RIS3 Assessment Wheel of Latvia - state government institutions and other Latvian researchers. Based on available information about RIS3 in all three Baltic States, authors will give their own opinion and evaluation about RIS3 in Latvia, Lithuania and Estonia using RIS3 Assessment Wheel.

The aim of the paper is to assess smart specialisation of Latvia, Estonia and Lithuania using smart specialisation assessment tool RIS3Assessment Wheel. The tasks of research are: (1) comparing already published versions of the RIS3 Assessment Wheel of Latvia and create articles authors' version; (2) create RIS3 Assessment Wheel of Lithuania and Estonia; (3) compare and evaluate the smart specialisation strategy development in Latvia, Lithuania and Estonia using the RIS3 Assessment Wheel.

\section{Materials and Methods}

The European Commission has developed a smart specialisation platform where information about the RIS3 Assessment wheel is published. It is an assessment tool for RIS3 development in a country or region. The assessment wheel includes different activities, e.g. self-assessments, peer-reviews, expert contributions, presentations at dissemination, discussion and negotiation meetings etc. RIS3 Assessment Wheel includes six steps - analysis of the regional context, governance (ensuring participation and ownership),elaboration of an overall vision for the region future, identification of priorities, coherent policy mix, monitoring and evaluation mechanisms. Each step consists of 3 critical factors. The scaling tool (from 0 to 5 ) of each factor measures the seriousness of the evidence provided in the process. The meaning of each critical scaling: 0 means no information available on the specific element, 1 means poor, 2 means to be 
improved, 3 means fair, 4 means strong and 5 means excellent. In this visual 'spider graph', it is easy to recognize the strengths and weaknesses, and it shows the necessary further activities such as completion or a rise of the national or regional RIS3; preparation and implementation of funding programmes; applicable consideration of territorial features, needs and priorities in multi-level governance process; reflexion on training needed in a specific defined segment and cooperation activities definition; benchmarking reviews and comparisons; the establishment of mutual learning or twinning tools (Foray et al., 2012).

In this article, the used tool RIS3 Assessment Wheel which allows evaluation of RIS3 development in the region or country is very subjective and assessment is informal. Therefore, it is very important to see the authors of each composed wheel because evaluation of the factors of a wheel depends on researchers' knowledge, experience and available information and information quality about each factor of the wheel.

The use of RIS3 Assessment Wheel step by step is described in RIS3 Guide. The first step is analysis of the regional context. The analysis consists of following critical factors: regional / national assets, outward dimension and entrepreneurial dynamics. It is necessary for asset in the regional context the existing assets to evaluate major regional strengths and weaknesses and to identify any innovation system bottlenecks and key challenges of economy and society. Smart specialisation central principle is economic differentiation. The idea of it is that by diversifying regional economy's unique, localised know-how into new innovations and combinations which are close to next to it, the regional economy has a possibility to build its competitive advantage. To evaluate this factor, expert assessments and targeted surveys, SWOT analysis and regional profiling studies can be used (Foray et al., 2012).

The next factor - outward dimension which identifies competitive advantages of region through systematic comparisons with other regions. The region should identify relevant flows of goods and linkages, services and knowledge releasing possible integration with partner regions. To evaluate this factor, interregional rounds of interviews and work groups, comparative studies) can be used (Foray et al., 2012).

The analysis of entrepreneurial dynamics gives a possibility to build a systematic understanding of economy and society areas with the future development greatest potential and areas need to be encouraged and extracted or that are ready to be tapped. For effective appreciation of entrepreneurial dynamic should improve statistics on entrepreneurial activities and entrepreneurial actors (firms, individuals and organisations with entrepreneurial knowledge) and management and governance bodies responsible for RIS3 engage in direct discussion. To evaluate this factor, consultation and auditing tools, interviews with firms and cluster management, observations and monitoring organisations mixed working groups can be used (Saublens, n.d.).

Step 2 - Governance: ensuring participation and ownership. In the first subsection - governance structures - it is necessary to identify specific bodies and define their tasks, roles and responsibilities. In the RIS3 process, such organisation types as public authorities, universities and other knowledge-based institutions, investors and enterprises, civil society actors, and international experts should be involved. Thus, both market and the civic society involvement are achieved. The next factor - broad participation shows interactive, consensus-based application of collaborative leadership principles speaking about quadruple helix - interaction between the academic world, public authorities, business community and innovative users. In collaborative leadership involved actors must manage conflict themselves, so requiring the emergence of collaborative practice. As the last factor of this step - management and communication speaks about the use of open forum discussion and citizen dialogue which nowadays can be solved with the e-governance tool. E-governance facilitates closer cooperation between society and governance (Foray et al., 2012).

Step 3 - Elaboration of an overall vision for the future of the region. It consists of following critical factors: broad view of innovation, grand challenges and scenario analysis. This step deals with shared comprehensive scenario of society, regional economy and environment by all stakeholders. It speaks about clear and shared future vision and main goals that should be achieved in the region. Future vision should involve all regional stakeholders (Saublens, n.d.).

Step 4 - Identification of priorities - consists of revision of past priorities, consistency and critical mass. Firstly, it is important to do a critical revision of past experiences, then align it with context analysis and harvest entrepreneurial discoveries. Smart specialisation involves making smart choices. The highest potential impact on the regional economy can be reached by selecting the right priorities and channelling resources towards the highest potential investments. Therefore, it is also important to mention concentration of resources to the limited number of priorities (Online S3 Platform:..., 2016).

Step 5 - Policy mix includes roadmap, balance and framework conditions. The roadmap is the most effective instrument to implement smart specialisation strategy. The roadmap could be an effective action plan which also allows experimentation through pilot projects. An action plan should contain consistent 
and comprehensive information about strategic aims, implementation timeframes, tentative budget allocation and identification of funding sources. But pilot projects generate the main tools for policy experimentation and allow testing policy measures before implementing them at a larger scale (Online S3 Platform:..., 2016).

Step 6 - Monitoring and evaluation with following critical factors: output and result indicators, monitoring and RIS3 update. This step considers the selection of a limited number of outputs and result indicators linked to priorities with clearly identified baseline and targets, then about mechanisms supported by appropriate data collection to verify how the actives in the RIS3 strategy are delivering the output and result targets and also about the revision of priorities and policy mix as a result of the monitoring exercise (Foray et al., 2012).

The European Commission collects the annual national report of each EU member state, so the national reports of Latvia, Lithuania and Estonia were used as main documents for creating RIS3 assessment wheels of all three Baltic countries by authors. There were also various other documents available at the beginning of 2017 used and authors' knowledge about the economic situation in Baltic countries. Each factor was studied carefully, and well-considered and wellgrounded decision of its assessment was made.

\section{Results and Discussion}

In Latvia, there has already been published two RIS3 Assessment Wheel of Latvias'RIS3 development. The first RIS3 Assessment Wheel was published by government officials in 2014 - the
Ministry of Education and Science, Deputy State Secretary A. Kiopa (Fig. 1.).

As seen in Fig. 1, there are some positions with evaluation 0 as there is no information available on the specific element - scenario analysis, roadmap, framework conditions and RIS3 update. But also some positions are evaluated as excellent - regional/ national assets, broad participation, consistency and output and result indicators. In general, some positions show good results, but it is seen that some factors should be improved.

In spring 2016, Latvian researchers M. Pelse and M. Lescevica published their own newer version of the RIS3 Assessment Wheel in Latvia (Fig. 2). In this version many factors are evaluated better, but there are just 2 factors with an excellent mark and no factors with 0 marks. As in the government wheel the evaluation of factors was drastically different, in this wheel more factors are better evaluated. Such an evaluation has been explained with new measurements, organising RIS3 popularising seminars and conferences and also developing new RIS3 supporting documents during this time. For further steps for RIS3 development, the national and regional RIS3should be upgraded; appropriate territorial features, priorities and needs in governance process at national level should be considered; funding programmes prepared and negotiated; reviews, comparisons and benchmarking done; reflection on training activity needed in a specific defined segment and cooperation activities defined and mutual learning tools established (Pelse \& Lescevica, 2016).

After another year RIS3 Assessment Wheel for Latvia looks different (Fig. 3). Most of positions

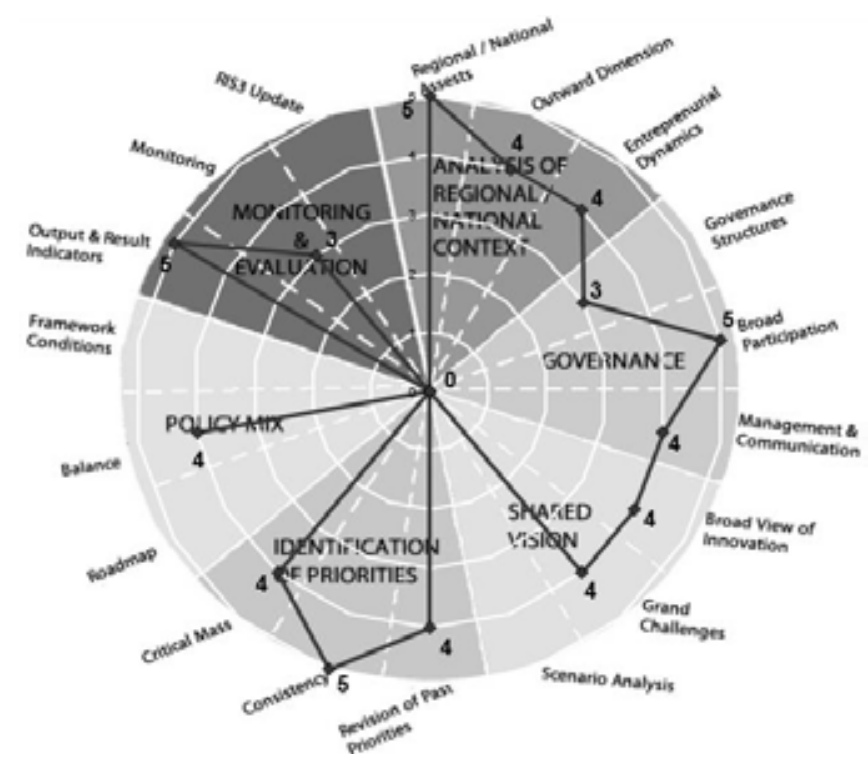

Source: Pelse \& Lescevica, 2016.

Figure 1. RIS3 Assessment Wheel of Latvia by government officials. 


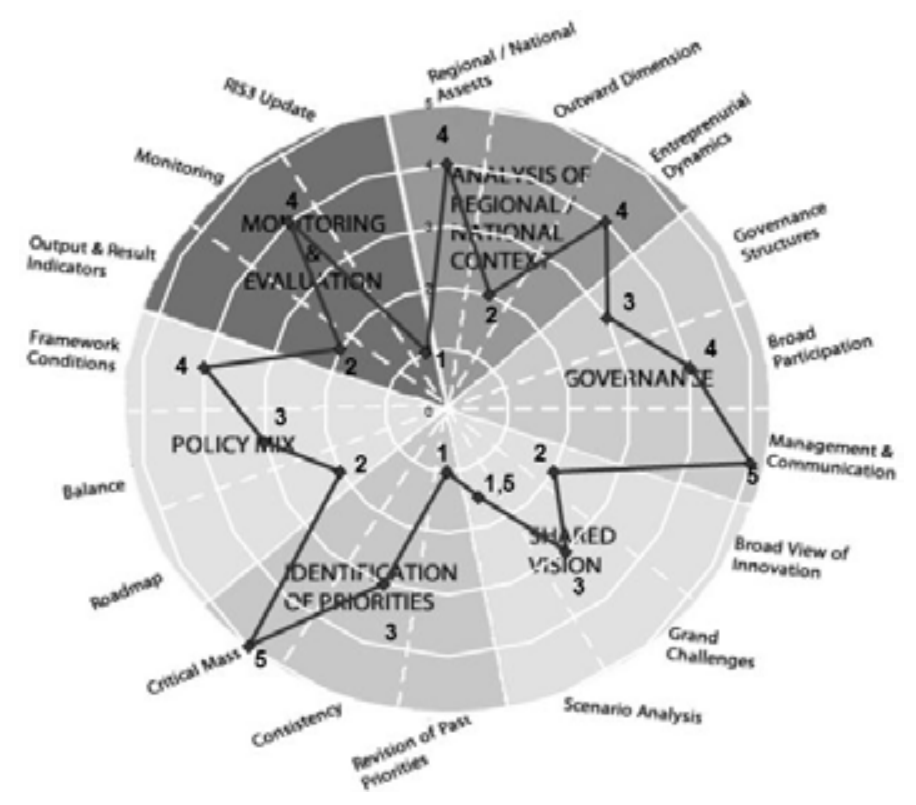

Source: Pelse \& Lescevica, 2016.

Figure 2. RIS3 Assessment Wheel of Latvia by other Latvian researchers.

article's authors evaluate not as highly as Latvian researchers Pelse and Lescevica in their assessment wheel and even also comparing with government opinion in 2014. About RIS3 Update and Roadmaps all three versions of assessment wheels coincide significant improvement should be made in these areas. Consistently good rating has such factors as regional/national assets, management \& communication, critical mass and monitoring. Since the beginning of the RIS3 development in Latvia, there have been many RIS3 popularising seminars and conferences organised, there is more and more new RIS3 documentation being developed, but the state has not accepted even the informative report of the Development of a Smart Specialization Strategy for Latvia yet and there is no law or other official government document on the state level about RIS3.

In articles authors' opinion, the most important step of the RIS3 Assessment Wheel is Monitoring \& Evaluation - it is the promoter of RIS3 development in the country of region. As seen in all versions of assessment wheel, during the years in Latvia the situation of RIS3 monitoring and evaluation has not improved yet. As there is no organised legislation

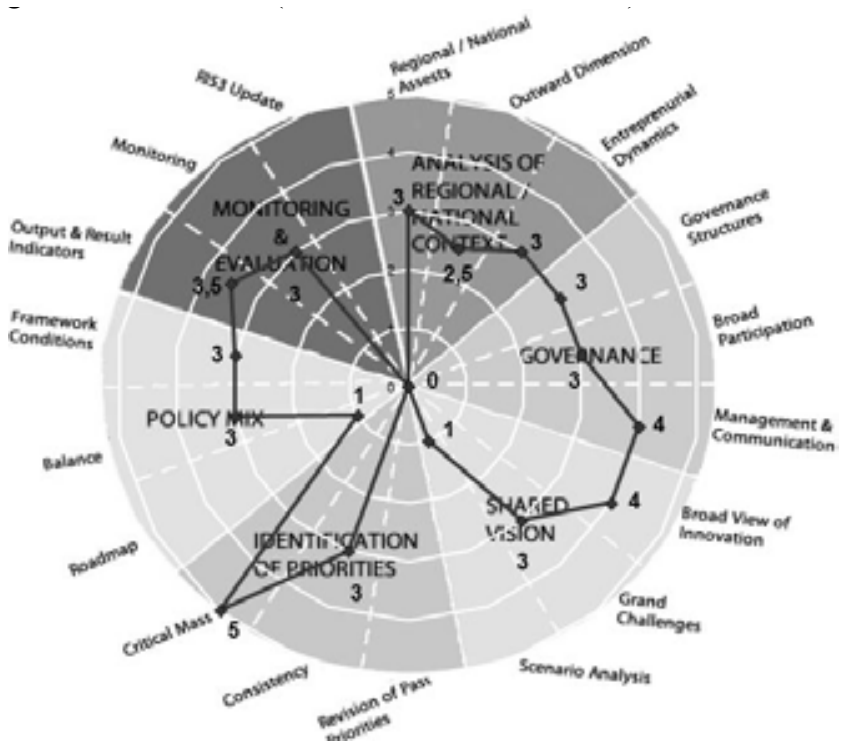

Source: authors' construction.

Figure 3. RIS3 Assessment Wheel of Latvia by articles authors. 


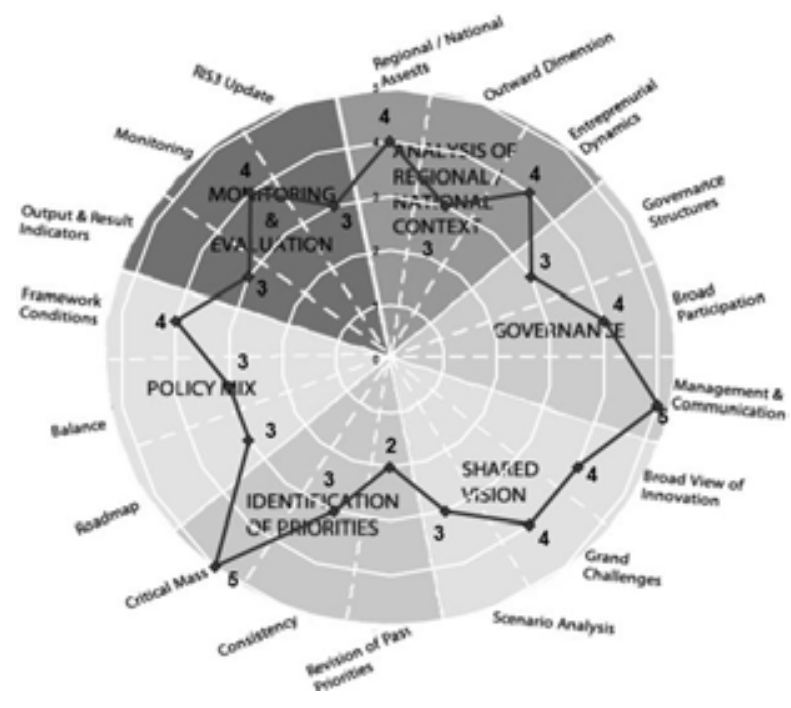

Source: authors' construction.

Figure 4. RIS3 Assessment Wheel of Lithuania.

about RIS3 on the state level, the monitoring and evaluation process goes on its own accord.

Low evaluation of all three versions of assessment wheels has a factor Scenario Analysis. In Latvia, there is low activity about RIS3 risk assessment and contingency plan for possible future changes (European Commission, 2016c). Responsible institutions for RIS3 development in Latvia should work more on this factor foreseeing possible risks and also contemplating and considering possible future changes of RIS3 development in organised conferences and seminars.

Generally speaking, 3 years have passed since the first assessment of Latvia's RIS3 was done, but comparing first two steps of the assessment wheel there are small differences in all three versions opinions. Governance related factors are unchanged because there are no changes in government policy; there is small activity from the government side.

RIS3 of Lithuania has a good evaluation in all factors (Fig. 4). Comparing article authors' assessment wheel version with RIS3 of Latvia - all factors are with the same or higher evaluation, which means that in authors' opinion RIS3 in Lithuania is developed better in all fields. In Lithuania, the Research \& Innovation policy mix has improved significantly in the context of the National Strategic Reference Framework 20072013 and the Lithuanian Innovation development programme 2014-2020 (Paliokaite, 2014).

Referring to governance investment in RIS3 development in Lithuania, the situation is similar to one in Latvia - governance should be more involved in RIS3 development process. In the Annual Report of Lithuania, they recognize that they still have weak governance systems and inadequate and fragmented research and innovation policy, thus impeding state transition to a more value-added economy. Although most reforms concerning state-owned enterprises are in place, there is still a need for ensurance of their implementation and compliance (European Commission, 2016d).

There are just 2 excellent evaluations of factors: Management \& Communication and Critical Mass because the state is interested in working on organising open forum discussions and citizen dialogues. Also, they have detected research fields, and limited RIS3 development priorities.

In Lithuania, special attention to RIS3 monitoring has been paid. Besides annual reports they have monitoring and evaluation mechanism where the actual implementation of priorities is monitored at the technology level. Each of 20 priorities in Lithuanian RIS3 can be broken down into a set of very specific technologies. The aim of the monitoring function is to assess how science and business applications compliment technologies (Lapienis \& Remeris, 2016).

The RIS3 of Estonia seems a little similar to RIS3 of Latvia, the same way as in the case with Lithuania, all factors have been evaluated equally or higher as articles authors' RIS3 of Latvia, except Management \& Communication factor. Comparing wheel of Estonia and wheel of Lithuania the evaluation of RIS3 development in both wheels is similar. In Estonian RIS3 wheel, two factors - Revision of past priorities and RIS3 Update have low rate, and also just two factors have excellent rate - Critical Mass and Governance structures. These factors are excellently rated because Estonians have clearly set three thematic fields on which smart specialisation strategy concentrates: ICT, health and resource efficiency. Also, they have defined collaboration between stakeholders - two ministries are involved 


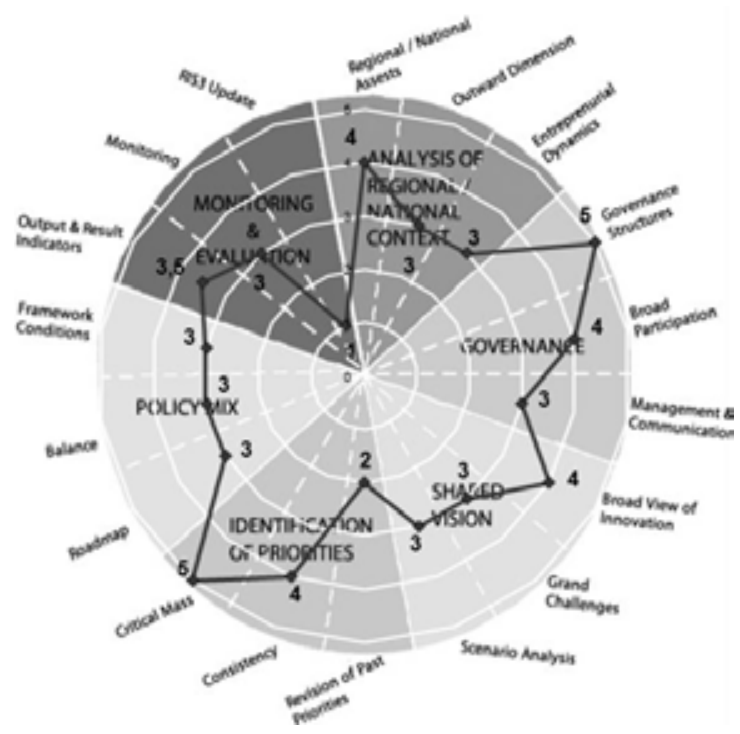

Source: authors' construction.

Figure 5. RIS3 Assessment Wheel of Estonia.

in policies and implementation related to research and innovation - the Ministry of Education and Research and the Ministry of Economic Affairs and Communications. Among the non-government expert bodies, the most outstanding and respected science policy advice organisation is the Estonian Academy of Sciences. Estonian Development Fund (together with the private sector) performs risk capital investments into new and growth-oriented technology. Although one review report stated that the general connection between sectoral ministries, societal stakeholders and the core research and development system is inadequate. There are too many organisations involved in implementing the innovation policies. Given the size of the country, the number of organisations is disproportionate; the main problem in the existing governance system is a lack of the main coordinating body (Eljas-Taal \& Hamza, 2013). Therefore, factor management \& communication is not so highly evaluated.

Estonia has in general a very high share of research and development expenditure within the GDP (European Commission, 2016a). Public sector research is above average, and Estonia has a large number of people with tertiary education. Speaking about the factor Outward dimension - it has a lower rate because in spite of active participation in Framework programme and other international programmes, the patterns of Estonian international cooperation have no specific orientation. Also, in the factor Entrepreneurial Dynamics, there is a need to focus on fewer and stronger clusters (European Commission, 2016b).

The factor Roadmap has a media evaluation because Estonian Rural Development plan 2014-2020 developed by state foresees smart specialisation as a possibility for small rural producers to specialise in niche products in order to survive in the competition. Also, Estonians have thought about RIS3 monitoring and are planning to introduce a systematic monitoring of the implementation of the smart specialisation creating an additional inter-ministerial monitoring body (Eljas-Taal \& Hamza, 2013).

\section{Conclusions}

1. RIS3 development assessment tool RIS3 Assessment Wheel is an informal tool evaluation whose result depends on assessing time, available information and authors' opinion.

2. Comparing three assessments done by government officials, other researchers and authors, one can conclude that in Latvia highly rated factors are 1) Regional/national assets, 2) Management \& communication, 3) Critical mass and 4) Monitoring. In article authors' opinion, the most important factor is Monitoring \& Evaluation as it is the promoter of RIS3 development in the country of region. Unfortunately, during the previous years in Latvia the situation of RIS3 monitoring and evaluation has not improved yet - there is no national legislation about RIS3 on the state level.

3. Situation analysis in Lithuania showed better RIS3 in comparison with Latvia - factors are evaluated by higher ratings, meaning that Lithuania is higher developed in all fields. The factors with highest ratings are two - Management \& Communication and Critical Mass because the state is interested in working on organising open forum discussions and citizen dialogues. Also, they have detected research fields and limited RIS3 development priorities. 
4. Estonia's RIS3 evaluation results are closer to Lithuania - all factors have been evaluated equally or higher than in Latvia, except the factor Management \& Communication. Two factors have excellent rate - Critical Mass and Governance structures. Estonian government has defined collaboration between stakeholders - sectoral ministries, societal stakeholders and the core research and development system.

5. In all three Baltic states, there is a lack of information available about revision of priorities in connection with RIS3 development. Therefore it can be concluded that in Latvia, Lithuania and also in Estonia there is low governance activity regarding to the RIS3 development and evaluation process. In order to achieve the aims set in RIS3, it is essential to finish work on RIS3 legislation in Latvia and introduce the systematic approach to RIS3 target evaluation in all Baltic States.

\section{Acknowledgements}

The research was supported by the project 'Strengthening Research Capacity in the Latvia University of Agriculture' (agreement No 3.2.-10/43).

\section{References}

1. Boekholt, P., Clar, G., Nauwelaers, C., Saublens, C., \& Tiits, M. (2015). Perspectives for Research and Innovation Strategies for Smart Specialisation (RIS3) in the wider context of the Europe 2020 Growth Strategy. European Commission. Retrieved February 28, 2017, from: http://ec.europa.eu/research/regions/ pdf/publications/ris3_report-082015.pdf.

2. Eljas-Taal, K., \& Hamza, C. (2013). Development of the Smart Specialisation Strategy in Estonia. Final Report. Retrieved February 28, 2017, from: https:/ida-viru.maavalitsus.ee/documents/119835/11381192/ Final_Report_RIS3_Estonia.pdf/2bd0c1ff-caca-4274-b7a2-dd152138525a.

3. European Commission. (2016). Council recommendation on the 2016 national reform programme of Estonia and delivering a Council opinion on the 2016 stability programme of Estonia. Brussels. Retrieved February 18, 2017, from: http://ec.europa.eu/europe2020/pdf/csr2016/csr2016_estonia_en.pdf.

4. European Commission. (2016). Country Report Estonia 2016. Brussels. Retrieved February 18, 2017, from: http://ec.europa.eu/europe2020/pdf/csr2016/cr2016_estonia_en.pdf.

5. European Commission. (2016). Country Report Latvia 2016. Brussels. Retrieved February 18, 2017, from: http://ec.europa.eu/europe2020/pdf/csr2016/cr2016_latvia_en.pdf.

6. European Commission. (2016). Country Report Lithuania 2016. Brussels. Retrieved February 18, 2017, from: http://ec.europa.eu/europe2020/pdf/csr2016/cr2016_lithuania_en.pdf.

7. Estonian Development Fund. (2013). Smart Specialisation - Qualitative Analysis. Retrieved January 3, 2017, from: http://www.arengufond.ee/wp-content/uploads/2013/04/Estonia_Smart_Specialisation_ Qualitative_Analysis.pdf.

8. Foray, D., Goddard, J., Beldarrain, X.G., Landabaso, M., McCann, P., Morgan, K., ... Ortega-Argiles, R. (2012). Guide to Research and Innovation Strategies for Smart Specializations (RIS 3). Retrieved December 15, 2016, from: http://ec.europa.eu/regional_policy/sources/docgener/presenta/smart_specialization/ smart_ris3_2012.pdf.

9. Informatīvais ziņojums 'Par viedās specializācijas stratēg̣ijas izstrādi' (Development of a Smart Specialization Strategy for Latvia: informative report). (2013). Retrieved December 13, 2016, from: http:// tap.mk.gov.lv/mk/tap/?pid=40291636. (in Latvian).

10. Lapienis, J., \& Reimeris, R. (2016). Lithuanian RIS3: how it was designed. Retrieved February 28, 2017, form: http://sumani2020.lt/documents/tyrimai_ir_ataskaitos/sumani2020_tyrimai_ir_ataskaitos_10.pdf.

11. Martinaitis, V., Martinaitis, Z., Paliokaite, A., Pundziene, A., Sakalys, A., Tamulaitis, G., ...Venskutonis, R. (2013). Identification of Specific R\&D\&I Priorities in Lithuania. Proposals for RDI Priorities. Retrieved January 3, 2017, from: http://s3platform.jrc.ec.europa.eu/documents/20182/89682/Proposals_for_Smart_ specialization_Lithuania.pdf/62c77005-c818-47bd-afba-6add66413a80.

12. Online S3 platform: methods and online assistants for RIS3. (2016). Retrieved February 28, 2017, from: http://www.onlines3.eu/.

13. Paliokaite, A. (2014). ERAWATCH Country Reports 2013: Lithuania. Retrieved February 28, 2017, from: https://rio.jrc.ec.europa.eu/sites/default/files/riowatch_country_report/ERAWATCH\%20Country\%20 Report\%20Lithuania\%202013.pdf.

14. Pelse, M., \& Lescevica, M. (2016). Smart Specialization Assessment in Latvia. Economic Science for Rural Development, 42, $126-131$.

15. Saublens, C. Research and Innovation Strategies for Smart Specialisation (RIS3): The steps. Retrieved February 28, 2017, from: http://know-hub.eu/knowledge-base/videos/research-and-innovation-strategiesfor-smart-specialisation-ris3-the-steps.html. 